\title{
Políticas de Pesquisa e Resistências em Tempos de Acirramento dos Processos de Violência
}

\author{
Giovana Barbieri Galeano ${ }^{1} \quad$ Neuza Maria de Fátima Guareschi ${ }^{2}$ \\ ${ }^{1}$ Universidade Federal do Rio Grande do Sul, RS, Brasil. $\quad{ }^{2}$ Universidade Federal do Rio Grande do Sul, RS, Brasil. \\ Andrea Cristina Coelho Scisleski ${ }^{3}$ \\ ${ }^{3}$ Pontifícia Universidade Católica do Rio Grande do Sul, RS, Brasil.
}

\begin{abstract}
Resumo: Neste artigo, tomamos os estudos de Hannah Arendt, Walter Benjamin e Giorgio Agamben para problematizar a Psicologia e as demandas que lhe são dirigidas em termos de empreender a produção de estratégias contra práticas violentas que tem crescido no contexto brasileiro contemporâneo. Para a presente discussão, designamos três analisadores principais: o primeiro é uma cena vivenciada em um parque da cidade de Porto Alegre - RS, cuja função como cenário é discutir como a Psicologia aborda questões relacionadas ao cotidiano no que tange a produção de conhecimento; o segundo considera os movimentos realizados por diversos grupos em todo o Brasil sob a hashtag “\#elenão"; finalmente, o terceiro focaliza o período após o primeiro turno das eleições presidenciais de 2018, quando o espaço público foi usado para dialogar sobre as propostas presidenciais dos candidatos para o segundo turno. A aposta éticoepistemológica e política de nossa pesquisa está ligada às lutas que constituem um espaço de resistência em relação às práticas violentas incitadas cotidianamente. Argumentamos que as lutas não dizem respeito apenas à afirmação da possibilidade de existência/vida, mas, principalmente, sobre a impossibilidade de não lutar.
\end{abstract}

Palavras-chave: Psicologia Social, Resistência, Políticas de Pesquisa.

\section{Research Policies and Resistance Policies in Times of Incitement of Violence Processes}

\begin{abstract}
In this article, we take Hannah Arendt, Walter Benjamin and Giorgio Agamben's studies to problematize psychology and the direct demands to produce strategies against violent practices that have been escalating in the contemporary Brazilian context. We designate three main analyzers to the present discussion: the first is a scene experienced in a park in the city of Porto Alegre - Rio Grande do Sul, which serves as an example to discuss how psychology approaches these daily-life issues of vulnerability related to knowledge production; the second regards to movements performed by several groups throughout Brazil, during the election period, under the hashtag "\#elenão"; finally, the third analyzer focuses on the campaign period for the second term of the 2018's presidential election when the public space was used to discuss candidates' presidential proposals. The ethical-epistemological and political bet of our research is linked to daily struggles that constitute a space of resistance to violent practices incited on a daily basis. We argue that struggles are not only related to the affirmation of the possibility to exist in society, but also to the impossibility of not struggling.
\end{abstract}

Keywords: Social Psychology, Resistance, Research Policies. 


\title{
Políticas de Investigación y Resistencia en Tiempos de Intensificación de los Procesos de Violencia
}

\begin{abstract}
Resumen: En este artículo, tomamos los estudios de Hannah Arendt, Walter Benjamin y Giorgio Agamben para problematizar la psicología y las demandas que se le dirigen en términos de emprender la producción de estrategias contra prácticas violentas que han crecido en el contexto brasileño contemporáneo. Para la presente discusión, designamos tres analizadores principales: el primero es una escena vivida en un parque de la ciudad de Porto Alegre - Rio Grande do Sul, cuya función como escenario es discutir cómo la psicología aborda temas relacionados con la vida cotidiana en términos de producción de conocimiento; el segundo analizador considera los movimientos realizados por diversos grupos en todo Brasil bajo el hashtag“\#elenão”; Por último, el tercer analizador se centra en el período posterior a la primera votación de las elecciones presidenciales de 2018, cuando se utilizó el espacio público para dialogar sobre las propuestas presidenciales de los candidatos para la segunda votación. La apuesta ético-epistemológica y política de nuestra investigación está vinculada a las luchas que constituyen un espacio de resistencia en relación a las prácticas violentas incitadas cotidianamente. Argumentamos que las luchas no se refieren sólo a la afirmación de la posibilidad de existencia/vida, sino principalmente a la imposibilidad de no luchar.
\end{abstract}

Palabras clave: Psicología Social, Resistencia; Políticas de Investigación.

\section{Introdução}

Esta escrita anuncia o nosso posicionamento em prol de uma forma de existir que não se renda ao combate e insista em não perder forças diante da empreitada, muitas vezes ineficaz, de fazer uso da razão para argumentar sobre a situação política e social que temos enfrentado no Brasil desde o período de eleições presidenciais no ano de 2018.

Nesse período eleitoral, asseveraram-se as práticas de ódio e intolerância com relação às diferenças, especialmente no que diz respeito à afirmação das existências nos espaços políticos. Ódio e intolerância emergiram como afetos diante do posicionamento partidário e/ou ideológico distinto, mesclando-se com questões referentes às relações de gênero e sexualidade, étnico-raciais, diferenças econômicas. Tais afetos produziram tensionamentos, e mesmo atos de violência, entre aqueles que pediam por intervenções militares, gerando um sentimento de vulnerabilidade naqueles que argumentavam pela democracia.

Importante destacar que tais práticas não foram produzidas somente nesse momento, uma vez que, para diversas parcelas da população, esse cenário é cotidiano e letal. A peculiaridade do recorte que se faz diz respeito ao espraiamento e ampliação dos sujeitos sobre os quais tais práticas violentas incidem.

Quais palavras poderiam ser utilizadas para caracterizar o infindável momento que temos vivido? Ânimos exaltados? Não, denominar assim seria pouco preciso. Os embates nas ruas, nas redes sociais digitais, têm sido travados entre corpos vociferantes que pouco se ouvem e pouco se fazem ouvir. Em contrapartida, as decisões políticas governamentais do Estado, tomadas no âmbito do direito, têm se operado de maneira silenciosa e naquele espaço de tempo entre a noite e a manhã. Nestes últimos tempos, no Brasil, nós, que apostamos na democracia, também temos ouvido pouco e nos assustado muito. Esse campo de disputa tem mostrado que é preciso ajustar a forma como nossas lutas têm sido empreendidas.

Carregamos - e produzimos - em nossos percursos acadêmicos, os elementos metodológicos e teóricos para empreendermos uma crítica (Benjamin, 1921/1986; Foucault, 2005) do que nos acontece, isto é, da organização/configuração do presente político/ social. Essa crítica, contudo, deve ressaltar a preeminência do encontro com a cidade, com as manifestações no espaço público e, especialmente, com o próprio modo como a realizamos. 
Neste texto, inspiramo-nos nos estudos de Hannah Arendt, Walter Benjamin e Giorgio Agamben com o objetivo de interrogar tanto à própria Psicologia, quanto às demandas que a ela - e, portanto, a nós têm sido feitas no que diz respeito à produção de uma leitura sobre o presente brasileiro. Problematizar o presente torna-se uma importante parte da agenda política para a Psicologia, na qual a intolerância com relação à diferença (de pensamento, posição política, crença, orientação sexual, identidade de gênero, dentre outras) tem extrapolado a ordem das vociferações para o empreendimento, efetivo, de ações violentas/ de extermínio político e biológico (Agamben, 2004; 2014). Por extermínio político denominamos a situação em que um sujeito é impedido de exercitar sua liberdade de escolha em conduzir sua própria vida e sofre processos de marginalização que o impedem de acessar seus direitos; enquanto que, por extermínio biológico, deve-se compreender a morte física, propriamente dita.

Dirigimo-nos a pensar, ao mesmo tempo, a produção de uma leitura do presente e a tentativa de estabelecer pontos de luta, novamente, bastante localizadas. Isto porque não é possível assumir todas as lutas, e é por esse motivo que estabelecemos redes com outras frentes. Nesta escrita, ora será utilizada a primeira pessoa do singular (para situar a produção escrita das cenas), ora a primeira pessoa do plural (no contexto das análises). Importante destacar que, no caso do uso da primeira pessoa do singular, optamos por não definir qual das autoras a realizou uma vez que se trata de um recurso linguístico para mantermos o estatuto de produção coletiva das análises, uma vez que a narração é coletiva e, como já escrevera Walter Benjamin, "ela não se esgota jamais. Ela conserva suas forças e depois de muito tempo ainda é capaz de desdobramentos" (Benjamin, 1936/2012a, p. 226).

As estratégias indicadas anteriormente permitem que possamos dar consistência ao conceito/ campo ao qual nos propomos constituir e analisar: o acirramento dos processos de violência, a partir da análise das ações empreendidas pelos elementos que compõem o que se denomina por Estado (os próprios sujeitos e suas instituições: polícia e direito, principalmente) e da problematização das lutas/posicionamentos realizadas pelas frentes de luta já existentes e, também, pela Psicologia. Ressaltamos que as tensões políticas/econômicas/sociais vividas atualmente não se reduzem ao cenário brasileiro, mas fazem parte de uma configuração histórica-social-geográfica que dá visibilidade ao projeto político e de sociedade em que está em jogo o asseveramento de práticas fascistas. Por práticas fascistas entendemos as políticas de anulação ou mesmo de morte do outro, como apontaremos adiante neste artigo.

Cabe mencionar que o acirramento da violência no cenário brasileiro não se trata de um evento isolado neste momento, em termos mundiais. Apesar de não ser a ênfase deste trabalho a discussão sobre o contexto internacional, não podemos deixar de mencionar como o caso do Brasil se insere em uma ampla lógica de políticas que afirmam violências, em diversos níveis, e práticas que visam combater às diferenças e às diversidades, quando não o próprio outro, que se apresenta. Os movimentos de uma emergência reacionária e conservadora se recrudescem configurando o contexto internacional, tomando a cena nos países europeus e nos EUA, dentre outros. Destacam-se, especialmente, as ações xenófobas, por exemplo, que se orquestram com a construção, defendida por Donald Trump, do muro na fronteira dos EUA com o México; com o Brexit, que, com a saída do Reino Unido da União Europeia, se diz salvaguardar aos britânicos uma identidade forjada na exclusividade de empregos, idioma e nacionalidade; e com os enunciados de Salvini que, muitas vezes em um tom macabro de um revival literalmente fascista, abdica prima gli italiani" ${ }^{1}$ Nada distante de uma "Alemanha para os alemães" parece ainda ecoar e chacoalhar o recente passado ocidental. Cenários assim facilitam a produção de certos mitos.

Contudo, é fundamental destacar que tais práticas não são homogêneas, bem como não o são as lutas que nos propomos a travar. Nesse aspecto, faz-se importante situar a quais lutas nos atrelamos, uma vez que compreendemos que não se trata do combate a uma grande figura maligna, mas sim ao agir cotidiano cuja finalidade é enfraquecer, nas relações micropolíticas, os enunciados de verdade que produzem práticas violentas. Ou seja, nossas lutas se situam não com vistas à destruição de uma suposta estrutura Estatal que seria produtora primeira da violência, mas, justamente, incidindo nas relações que fazem a manutenção de práticas violentas.

\footnotetext{
1 "Primeiro os italianos".
} 
Para a presente discussão, designamos três analisadores principais: o primeiro é uma cena vivenciada em um parque da cidade de Porto Alegre - RS, cuja função como cenário é discutir como a Psicologia aborda questões relacionadas ao cotidiano no que tange a produção de conhecimento; o segundo analisador considera os movimentos realizados por diversos grupos em todo o Brasil sob a hashtag "\#elenão"; finalmente, o terceiro analisador focaliza o período após o primeiro turno das eleições presidenciais de 2018, quando o espaço público foi usado para dialogar sobre as propostas presidenciais dos candidatos para o segundo turno. A aposta ético-epistemológica e política de nossa pesquisa está ligada às lutas cotidianas que constituem um espaço de resistência em relação às práticas violentas incitadas cotidianamente. Argumentamos que as lutas não dizem respeito apenas à afirmação da possibilidade de existência/vida, mas, principalmente, sobre a impossibilidade de não lutar.

\section{Sobre o ajuste de foco e da localização das lutas}

Há lagos na Redenção, parque localizado na Avenida João Pessoa, em Porto Alegre. Foi em um desses lagos que, em uma quarta-feira cinzenta, o choque cotidiano com as cenas da cidade estremeceu meu chão da Psicologia: de quatro, debruçado sobre um lago do Parque, estava um homem escovando os dentes com a água lodosa que serve de conteúdo para aquele lago. Por um instante o olhar daquele homem cruzou com o meu. Silêncio.

As primeiras tentativas de compreensão daquela imagem esgotavam a vida que insistia em existir na Redenção, contudo, não foi difícil analisar o contexto no qual aquela vida existia. Dentre tais tentativas, reportei-me à Psicologia preocupada com a saúde, afinal as análises sobre as condições insalubres daquele local apontavam, como efeito, para a exposição a diversas doenças. Além disso, fez-se presente a Psicologia estremecida com as questões sociais, pois, não seria um fato que as condições nas quais aquele homem estava eram vulneráveis? Por fim, mas não em uma ordem cronológica, flertei com o tentacular direito: era uma violação de todas as determinações legais que nos atribuem um estatuto jurídico. Não olhei para o fato de que, mesmo sendo o lago a fonte da água utilizada, o homem escovava os dentes. A primazia do olhar me impediu de ver que havia ali um cuidado daquele homem consigo mesmo.

É possível argumentar que esse cotidiano é velho, inclusive visto em outras cidades, e que os questionamentos levantados com relação à Psicologia também têm sido tema de exaustivos debates. Mas não seria possível, ainda, argumentar que, apesar da velhice, tais imagens não caducam? Isto é, não se tornam obsoletas, afinal, desenvolvemos surdez e cegueira, uma vez que "nos acostumamos a ver e a ouvir certas coisas que, por fim, não precisamos nos esforçar para compreendê-las"? (Galeano, 2017, p. 48).

A imagem não apenas expõe as condições vulneráveis de existência daquela vida ao iluminá-la, mas visibiliza, justamente, a violência empreendida pelo Estado pela constituição do cenário em que a imagem emerge. É possível argumentar, mais uma vez, que a adjetivação de vulnerável à condição na qual se encontrava o homem é uma leitura arbitrária, contudo, não seriam arbitrários, muito embora rigorosos e legitimados, todos - ou, no mínimo, boa parte - os elementos que constituem a ciência? A facilidade com que se é possível produzir certas análises, como a que foi feita sobre o homem na Redenção, contrasta com a tarefa dificílima de realizar um diagnóstico das forças que, de fato, incluem-nos como elementos em jogo no presente. Afinal, não estamos também nós - psicólogas, professores, estudantes, pesquisadores, policiais, ativistas, líderes comunitários, militantes das mais diversas frentes - em uma zona limite entre o privilégio de podermos dizer o que pensamos e o risco efetivo de também ser o objeto da violência?

Havia, apesar de toda a afetação pelas condições do homem, a posição privilegiada de pesquisadora que lia aquela imagem, ao mesmo tempo em que a produzia enquanto elemento de análise. Compreender essa posição nos demandou realizar um movimento de ajuste do foco para o cenário, uma vez que argumentamos que assim se torna possível constituir estratégias de lutas frente às práticas de violência. Esse ajuste de foco se justifica, ainda, pelo fato de que o jogo político reorganizou, muito rapidamente e com uma força difícil de mensurar, o ódio e as formas de materialização do mesmo.

O presente do qual nos ocupamos deve ser localizado na luta entre a afirmação da possibilidade de existência/vida e os processos de asseveramento da violência visibilizados, especialmente, contudo não 
unicamente, nas cotidianas práticas de ódio, intolerância, produção de vidas invisibilizáveis/matáveis (Scisleski, 2010). Produzir uma leitura se constitui pela estratégia de, ao mesmo tempo, compreender o que está acontecendo e dialogar com as estratégias que consideramos cabíveis de empreender.

Para a realização de tal leitura conjugamos duas principais táticas. Uma delas se refere ao uso que fazemos das notícias veiculadas pelas mídias impressas e digitais e trabalhos publicados sobre a temática da presente discussão. A outra é a escrita de cenas vividas pelas autoras do presente texto, essas cenas não são representações ou descrições de algo como a realidade, mas carregaram a capacidade de chacoalhar a memória, permitindo-nos pensar sobre as situações tornadas desimportantes pelo movimento frenético da vida cotidiana (Benjamin, 1936/2012a; 1940/2012b).

Há, dentre muitos, um elemento que compreendemos ser importante no tensionamento da relação entre violência e resistência: a memória. A relação criada com as cenas é, assim, uma das nossas vias de luta, especialmente diante do argumento de que o Brasil seria um país sem memória (Rocha, \& Eckert, 2000). Ademais, enfrentamos uma tarefa que não é da ordem do desconhecimento. Não é, somente, pela via da apresentação de fatos e argumentos documentados que devemos empreender nossas batalhas, uma vez que a forma como as relações têm se estabelecido no que diz respeito a essas estratégias têm sido insuficientes para mobilizar e impedir que as práticas cruéis e incomensuráveis de violência sejam empreendidas.

Basta nos dirigirmos às atuais declarações sobre uma possível comemoração do Golpe Civil-Militar de 1964, que seria autorizada a se realizar no dia 31 de março de 2019. A comemoração se daria em referência ao fato de que o Golpe de 64 teria recolocado o país nos trilhos da história, uma vez que o grande mal do comunismo espreitava a pátria (Carta Capital, 2019). As torturas e desaparecimento de pessoas durante o Regime Militar, nesse sentido, ou são negadas ou justificadas pelo bem maior da nação, mesmo diante de todos os estudos desenvolvidos e documentos sobre tais ações. Quanto a esse último aspecto, Foucault (2008a) já apontava como sendo uma estratégia de gestão do Estado o aniquilamento de determinada parcela da população para que outra pudesse viver mais e melhor. Nessa esteira da tanatopolítica, seguindo o pensador francês, a cisão popu- lacional é fomentada de modo que esses que venham a ser excluídos e exterminados sejam visibilizados ou contabilizados como marginais que pesam - social e economicamente - aos ombros do cidadão de bem, justificando, assim, as eventuais ações de violência que possam ser empreendidas.

Dentre tais elementos tornados desimportantes está a Comissão Nacional da Verdade (Lei № 12.528, 2011) cuja finalidade se dirige a examinar e esclarecer as violações de direitos humanos praticadas durante o período de ditadura civil-militar. O próprio texto da Lei $\mathrm{n}^{\circ} 12.528$ (2011) explicita que o objetivo da Comissão é o de "efetivar o direito à memória e à verdade histórica e promover a reconciliação nacional”.

Recorremos à tarefa da memória enquanto estratégia de luta, pois o passado que não se realizou é o que tensiona o presente. Memorar é difícil porque não se trata somente de uma imagem no pensamento, a ação de memorar recruta o corpo como um todo, produz sensações, por vezes, pouco agradáveis. Em alguns casos, memorar dói e faz com que nos demos conta de que aquilo que se passou não ficou para trás. É preciso coragem e, por essa razão, também é preciso fazer com que esse passado - que não está distante no tempo - soe em nosso cotidiano, especialmente em tempos em que a validade das coisas/informações expira em seguida de sua produção. Apenas trazer a ordem do dia também não é suficiente, nossas lutas devem como sugeriu Gagnebin (2018, p. 67) sobre a proposição de história de Walter Benjamin: "fazer emergir as esperanças não realizadas desse passado, inscrever em nosso presente seu apelo por um futuro diferente".

\section{Processos de violência e a convocações à luta}

O acirramento dos processos de violência tem, efetivamente e em medidas variáveis, produzido e ampliado os alvos de ações de extermínio: a impossibilidade da palavra no espaço público, a interceptação da diferença, o encarceramento sem provas, a destituição do elemento político das políticas públicas, pela precarização e desinvestimento das mesmas, e a definição das subjetividades autorizadas a existir e produzir-se no espaço público. Diante disso, não nos cabe direcionar discussões, neste momento, somente em prol da garantia de direitos, uma vez que tal investida não nos possibilitaria produzir outras formas de articulação potentes para fortale- 
cer as relações políticas/sociais, mas, sim, amarrar-nos-ia a uma frágil crença de que o direito (a lei), por si só, é capaz de garantir justiça. Cabe ressaltar, no entanto, que o campo jurídico-legal não deixa de ser um espaço de luta, uma vez que é também pelo direito que as condições de vida podem ser acessadas, especialmente no que concerne às populações que têm sofrido processos de marginalização/violência econômica, social e cultural.

Enquanto pergunta que nos direciona no desenvolvimento das reflexões aqui presentes, pensar sobre as lutas que nos propomos a empreender também faz com que nós realizemos deslocamentos nos próprios modos como temos compreendido as formas pelas quais as nossas pesquisas em Psicologia têm incidido nos espaços políticos, sociais e acadêmicos. Isto é, colocar em discussão qual é a nossa função enquanto pesquisadoras, e como ocupamos não apenas os espaços sobre/com os quais produziremos análises/ estratégias, mas, também, de que modo ocupamos a Psicologia enquanto ciência e profissão. Dizer isso é, em fato, afirmar o tipo de Psicologia que desejamos criar e afirmar.

Por um lado, o compromisso social da Psicologia (Miron, \& Guareschi, 2017) e os efeitos da produção de conhecimento, implicação política e função na gestão da vida (Bernardes, \& Marques, 2016; Rose, 2008) já são objetos de discussão quase totalmente encerrados na certeza de que não há cisão entre a ciência e o âmbito político/social. Por outro lado, também é assunto bastante problematizado a relação íntima entre violência e saber, nos termos em que esse saber venha a ser operado verticalmente com relação à vida.

Nessa esteira de pensamento, a Psicologia tem se atrelado aos processos de violência tanto como o elemento que auxilia na manutenção dessa violência, quanto como resistência à mesma. A convocação da memória obriga a pensar que, primeiramente, a implicação política da Psicologia não é um elemento óbvio e sempre presente na constituição dessa ciência/profissão. Ademais, mesmo atualmente existem movimentos dentro da própria categoria que têm, ao contrário da proposta de discussão do presente artigo, corroborado a existência e insistência de violências contra os sujeitos.

Tomemos, historicamente, as ações empreendidas pela Psicologia no período de regime ditatorial civil-militar brasileiro (1964-1985). Nesse período foi possível visibilizar "o predomínio de abordagens individualistas, descontextualizadas e apoiadas em modelos abstratos de seres humanos" (Scarparo, \& Guareschi, 2007, p. 100), combinadas com proibições de acesso às bibliografias entendidas como subversivas, tais como "notícias e textos sobre práticas emancipatórias desenvolvidas na Europa e obras de Paulo Freire, Guattari, Laing e Cooper" (Scarparo, \& Guareschi, 2007, p. 101).

Muito embora nesse contexto de ditadura tenham emergido discussões sobre os limites teóricos utilizados até então, além de ações coletivas e práticas em comunidades, empreendimentos, por parte da Psicologia, foram responsáveis por respaldar as violências/ violações executadas nesse período. Não se trata, aqui, de julgar os agentes, mas visibilizar a forma como as condições políticas/sociais possibilitam a constituição das práticas mantenedoras das lógicas repressivas, bem como convocam aos enfrentamentos.

Entendemos que as violências de Estado não acontecem de forma isolada, pois apenas são possíveis de serem sustentadas devido a uma rede de sujeitos que, através dos seus saberes e práticas, respaldam tais violências. Esses respaldos podem ser realizados de diversas formas como, por exemplo, através da elaboração de laudos, consultas e assinaturas em documentos que legitimem ações ou determinados modos de entender os sujeitos. Se não existissem profissionais que, com suas práticas, respaldassem as violências, talvez a época de ditadura não tivesse durado vinte e um anos e obtido o efeito repressor que teve (Scarparo, Torres, \& Ecker, 2014, p. 66).

Durante a ditadura civil-militar estava presente a ideologia de segurança nacional e desprezo pelo sistema político vigente até então (Silva, 2017; Scarparo, Torres \& Ecker, 2014) que permitiu não apenas justificar, mas legitimar as ações violentas e de violação de direitos direcionadas à população - ou a parte dela -, tais como a restrição dos direitos políticos e civis (Carvalho, \& Benvindo, 2017) e também torturas e coerções físicas (Oliveira, 2011). Nesse contexto, portanto, as possibilidades de resistência, isto é, afirmação da possibilidade de lutar e denúncias contra as ações do Estado foram, violentamente, reprimidas.

Não é um acaso, como podemos visibilizar, o endereçamento da pergunta: quais lutas nos propo- 
mos travar em tempos de acirramento dos processos de violência estatal? Quando recorremos às famosas expressões foucaultianas sobre pensar o presente, fazer análise do jogo entre saber-poder ou, ainda, pensar sobre a constituição das possibilidades de emergência/atualização de estratégias do governo da vida, o que estamos fazendo é nos perguntarmos “o que está acontecendo?". A pergunta implica o questionamento de uma ação que não se finalizou. O "acontecendo" é uma cena em movimento. Nossa tarefa é produzir uma imagem do presente a partir da leitura dessa cena.

Tal configuração, atrelada à intolerância, foi asseverada no período de eleição transcorrido no ano de 2018, em que dois principais candidatos concorriam à presidência do Brasil: Fernando Haddad (candidato pelo Partido dos Trabalhadores - PT) e Jair Bolsonaro (candidato pelo Partido Social Liberal - PSL). Nesse período, as disputas não se restringiram às urnas, mas ocuparam as ruas do país, não apenas para a organização de passeatas, mas pela tomada dos espaços públicos para a afirmação do direito, principalmente, o de existir e de livre manifestar-se (Kalil, 2018).

As mobilizações \#elenão tiveram início por organizações online, nas quais o "ele" sobre quem a escolha deveria ser "não" se tratava de Jair Bolsonaro, cujas declarações intolerantes e de conteúdo de ódio ganharam visibilidade de diversas formas. Tais afirmações passaram a ser visibilizadas tanto como perigo com relação à possibilidade de se institucionalizar enquanto política de estado legitimamente representada na presidência; quanto como possibilidade de autorização dos atos violentos enunciados pelo referido candidato à época, escoando em práticas cotidianas em que as ações violentas foram tornadas autorizadas a manifestarem-se.

Cabe dizer, no entanto, que diversos discursos de ódio e intolerância, tais como ofensas étnico-raciais, apologia ao extermínio de grupos populacionais marginalizados, apologia ao estupro como forma de punição, dentre outros, também foram sustentados no critério de livre manifestação ou, ainda, no direito de liberdade de expressão. Importante destacar que tais práticas não são produzidas somente neste momento presente, uma vez que, para diversas parcelas da população, esse cenário é cotidiano e letal. Do mesmo modo, é importante destacar que os momentos críticos referentes à produção de marginalização social, criminalização de certas categorias populacionais, assassinatos e demais crimes contra os grupos minoritários/marginalizados/em situação de vulnerabilidade (Carmo, 2016) tampouco são temática nova no contexto brasileiro. A peculiaridade do recorte que se faz, diz respeito ao modo como diversas práticas violentas não só foram estimuladas, mas acirraram-se as formas de sua expressão.

O resultado do primeiro turno que levou Fernando Haddad e Jair Bolsonaro para a fase final da eleição, fez com que diversos grupos por todo país, dentre os quais de vinculação acadêmica, também asseverassem as estratégias de "virar voto". Tais estratégias caracterizaram-se, de maneira geral, pela ação nos espaços da cidade cujo alvo eram os eleitores indecisos e que gostariam de conversar sobre as escolhas a serem empreendidas.

Ao ir às ruas para conversar com as pessoas que estivessem disponíveis a dialogar sobre a escolha do voto, o que encontramos foi, ao contrário, uma indisponibilidade visibilizada em vociferações cristalizadas em frases, tais como, "o Brasil não vai virar uma Venezuela", "Nossa bandeira jamais será vermelha". Quando nos questionavam sobre o porquê de estarmos ali (para conversar sobre o segundo turno das eleições) e, principalmente, quem éramos nós (estudantes e professores), as reações eram imediatas e precisas: simplesmente iam embora ou acusavam-nos de tentar mudar a opinião das pessoas, de sermos "comunistas", perguntavam, ainda, para qual partido estávamos trabalhando.

As tentativas de conversa e, portanto, do estabelecimento de uma relação não violenta, no sentido de interceptação e anulação do outro, resumiam-se a tentativas de explicitação de uma inocência que deveríamos provar para que fosse possível estarmos no meio da rua com cartazes nas mãos convidando para uma troca de ideias. Éramos nós, também, os objetos para os quais o ódio ao PT, ao nominado comunismo ao qual estaria rumando o Brasil, incidia. Nesses encontros, pouco pudemos falar e pouco também foram válidas as iniciativas de explicitar os planos de governo de cada um dos candidatos ou de desfazer os equívocos sobre venezuelas, comunismos, PTs.

Ao analisar essas ações foi possível avaliar que não se tratava, somente, de uma questão de compreensão. O ódio, naquele espaço, apontava para um processo de violência que extrapola o âmbito instrumental/tecnológico em que uma violência poderia se fazer visível. Aquelas pessoas, aqueles corpos, cujas 
vozes ecoavam na Praça da Alfândega em Porto Alegre, estavam sofrendo e com medo. A distância entre os corpos vociferantes e os nossos corpos calados era preenchida por uma quase que imobilidade.

Recorremos à tarefa de colocar em diálogo, neste momento, Hannah Arendt e Walter Benjamin, uma vez que compreendemos a possibilidade de estabelecer uma conversa entre os autores, especialmente com relação a dois principais textos, respectivamente, Sobre a violência e Crítica da violência - crítica do poder que, muito embora distintos, permitem pensar estratégias de leituras e lutas.

Arendt (2018) em seu escrito intitulado Sobre a violência argumenta que poder e violência são termos opostos, uma vez que a existência absoluta de um significaria a inexistência do outro. Os termos, no original em alemão, também são distintos. A autora utiliza Macht, traduzido em português como poder e Gewalt, com tradução em português enquanto violência.

Por sua vez, Benjamin (1921/1986) em Crítica da violência - crítica do poder, realiza sua análise utilizando o termo em alemão Gewalt que, segundo nota da tradução, carregaria uma ambiguidade, podendo significar tanto violência quanto poder. As discussões de Benjamin (1921/1986) nos colocam a questão de que a crítica da violência/poder teria espaço no que ele denomina de relação éticas, situadas no ponto entre os conceitos de direito e justiça.

As questões terminológicas não são irrelevantes, muito pelo contrário, elas dão visibilidade ao caráter conceitual atribuído aos termos poder e violência e, portanto, dizem respeito a forma como os autores construíram seus arranjos teóricos. Levando em conta que a nomeação dos termos é fundamental porque enunciam as formas pelas quais nos relacionamos com o que nomeamos. Dessa forma, nomear exerce uma função política (Agamben, 2005). A seguir, apresentamos uma figura com a finalidade de visualizarmos as referidas diferenças terminológicas.

Arendt (2018) e Benjamin (1921/1986) ajudam-nos a pensar sobre a historicidade da violência e do poder, uma vez que, para ambos, é possível afirmar que tais elementos não se atrelam à interioridade humana, mas, ao contrário, ao espaço que se estabelece entre os sujeitos, isto é, derivam do agir político. Os corpos vociferantes da Praça da Alfândega poderiam não saber da existência dos autores aos quais nos referimos, tampouco sobre as conceituações com as quais nos atrelamos para realizar uma leitura do que acontece no presente, mas, definitivamente, naquele espaço produzimos, em conjunto, relações de violência e poder muito bem localizadas.

Se à Hannah Arendt interessou o estudo da violência no âmbito da política, por ela definida como o espaço entre os homens, para Walter Benjamin, por sua vez, tratava-se do estudo do poder/violência no âmbito da origem e manutenção do direito e do poder jurídico. Enquanto os corpos vociferantes e os corpos calados constituem a imagem da fragilidade do espaço entre os sujeitos, o direito/lei pouco barulho faz, entretanto, igualmente mostra sua força. Ademais, para Benjamin (1921/1986, p. 167) uma resolução não violenta "jamais pode desembocar num contrato jurídico. Embora este tenha sido firmado pelas partes contratantes num clima de paz, ele leva, em última instância, à possível violência" uma vez que "todo poder/violência enquanto meio é ou instituinte ou mantenedor do direito".

Tais considerações nos levam a argumentar que, por um lado, a fragilidade do espaço entre os sujeitos não é da ordem da fraqueza ou assume caráter negativo. Esse espaço político que se efetiva no encontro

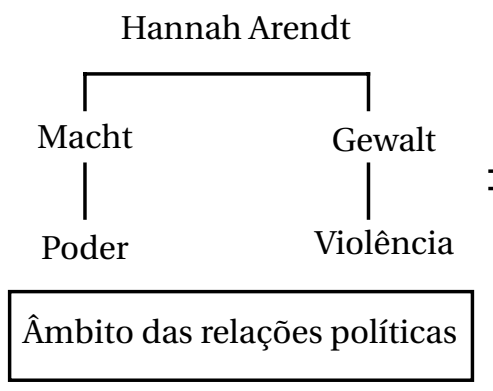

Walter Benjamin

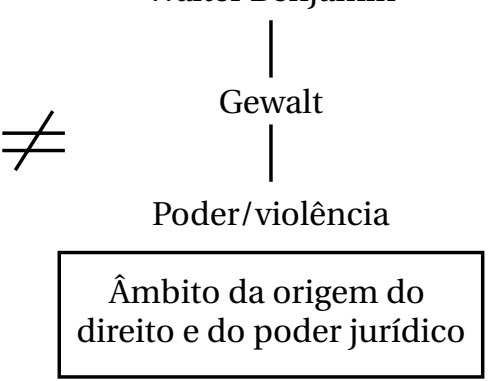

Fonte: Elaborado pelas autoras.

Figura. Poder e violência em Hannah Arendt e Walter Benjamin. 
entre diferentes é, justamente, aquele que nos permite estabelecer pontos de luta e, com esperança, ruptura em relação às lógicas violentas que insistem em produzir a destituição das possibilidades de discussão, troca, reflexão coletivas. Não se trata, por assim, de uma tentativa de produzir uma posição homogênea e unívoca diante das problemáticas sociais, mas de multiplicar as vias de análise e discussão.

Por outro lado, se tomarmos as questões de âmbito jurídico-legal sobre as quais Benjamin (1921/1986) discute o conceito de violência e a impossibilidade de justiça na dimensão da lei, pode-se visibilizar o efeito destituidor, apesar de silencioso e sorrateiro, que um elemento jurídico pode ter como efeito. No último dia 11 de abril de 2019, por exemplo, foi assinado o Decreto $\mathrm{n}^{\circ} 9.759$ que extingue e estabelece diretrizes, regras e limitações para colegiados da administração pública federal direta, autárquica e fundacional (2019). Os seus dispositivos legais, especialmente os decretos, têm sido elementos estratégicos de gestão utilizados para minar as vias de participação da sociedade no âmbito das decisões políticas, uma vez que os órgãos colegiados são responsáveis por elaborar, fiscalizar e decidir sobre determinada política pública.

Exaustiva e, aparentemente, pequena, os efeitos das ações na Praça da Alfândega não podem ser mensurados com exatidão. Pouco se falou, de fato, na opção de virar votos durante as conversas, já que nos interessava, também, a relevância dos meios da ação humana, mais do que com relação aos fins. Quanto a esse último aspecto, segundo Arendt (2018, p. 18) em razão de que os fins não poderiam ser previstos de maneira confiável "os meios utilizados para alcançar os objetivos políticos são muito frequentemente de mais relevância para o mundo futuro do que os objetivos pretendidos". Nesse sentido, os meios sejam eles as leis, decretos ou as ações em praças, ruas, parques devem ser nossos alvos de lutas, uma vez que a possibilidade de modificação de um determinado contexto se situa, justamente, nesse encontro/acontecimento político.

Apesar das localizações de suas definições terminológicas, Hannah Arendt e Walter Benjamin podem ser aproximados, ainda, no sentido de que, para ambos, não é pela lei (em si), mas pela produção de uma inoperosidade/desobediência com relação ao meio violento que as estratégias de resistências/ lutas podem ser realizadas. Arendt (2018), mesmo diferenciando poder e violência, afirma que nada é "mais comum do que a combinação de violência e poder" (p. 63) de modo que "onde os comandos não são mais obedecidos, os meios da violência são inúteis" (p. 65). Isto é, a aposta, aqui, é na criação dos tensionamentos somente possíveis pelo exercício de pensamento/discussão e não pelo reclame a leis mais duras/severas. Por sua vez, Benjamin (1921/1986), como dito anteriormente, afirma que não está, no direito/lei, o meio não violento ou garantidor da justiça, mas na linguagem.

Argumentamos em outro ponto da presente escrita que nossa aposta é na criação de espaços de resistência em que não esteja em questão a aniquilação das diferenças ou produção de homogeneidade de pensamento, mas na produção de tensionamentos, pois, é assim, nas relações localizadas e situadas no encontro com o outro, que se pode constituir uma outra história ou, ainda, a criação de uma história possível.

\section{Sobre a impossibilidade de não lutar: recusas e escolhas}

Para iniciar, duas questões. A primeira: houve algum momento em que não estivemos em luta? A segunda: podemos, no presente, não lutar? A primeira questão pode ser respondida com um não bastante seguro e já foi, inclusive, indicada no desenvolvimento desta escrita. A luta, ao contrário da conotação negativa que pode assumir, não deve ser tomada como um elemento que destitua o outro. A produção de conhecimento só é possível em razão de lutas, assim como a criação do cotidiano, das relações, dentre outros tantos âmbitos da vida. Isso não é naturalizar a luta, mas tomá-la enquanto possibilidade de ação.

Em uma luta nos colocamos em relação com o outro, seja ele um outro sujeito, instituição, formas de pensar (racionalidades), etc. Há o tensionamento do espaço entre um elemento e outro que se coloca em movimento. O que está em questão em uma luta desse tipo não é o vencedor ao final, mas a luta enquanto o próprio meio, seguindo os estudos de Hannah Arendt e Walter Benjamin indicados anteriormente. Se tomarmos, ademais, os trabalhos de Foucault (2005b, 2008a, 2008b, 2013, 2014, 2015) sobre as relações de poder-saber também compreenderemos que nos constituímos enquanto sujeitos pelo embate junto a esses elementos. A segunda pergunta se constitui, diferentemente da primeira, 
enquanto mais trabalhosa de problematizar. Podemos nós, no presente, não lutar? É acerca desta última questão que argumentamos se inserir a interrogação sobre as lutas a serem travadas e o modo como o asseveramento dos processos de violência tem incidido sobre o presente.

A interrogação sobre as lutas faz emergir uma outra: o que podemos nós, enquanto pesquisadores em Psicologia Social? Certamente, fazer uso da posição privilegiada que ocupamos no conjunto da sociedade, uma vez que, mesmo de modo parcial, localizado, talvez pouco certeiro, ainda temos espaço de fala junto a alguns coletivos, sejam eles os grupos com os quais produzimos conhecimento, os espaços coletivos de discussão, a participação em frentes de lutas e, também, as representações em autarquias.

Temos vivenciado um misto de esperança e assombro que, ao contrário da imobilização produzida pelo terror e medo, têm nos disparado para ação, para as lutas. Como afirmou Agamben em uma entrevista para o blog da Boitempo Editorial (2014) "o pensamento é a coragem do desespero". Durante 13 anos (correspondente aos governos Lula e Dilma, até o impeachment) colamo-nos a pauta prioritariamente ligada ao direito, garantias e acesso e não pudemos capturar a forma como já estavam sendo gestadas as articulações políticas, em termos de organização, que produziram como efeito nosso atual cenário: a atualização de práticas fascistas que se espraiam com rapidez tal que nos deixa sempre um passo atrás.

O que quer dizer estar um passo atrás? Significa que a forma de resistência tem se dado enquanto reação às ações violentas. Quando somos demandados a responder sobre o que pode a Psicologia frente à violência, continuamos a reificar a violência enquanto objeto de análise/intervenção. Mesmo neste texto, quando nos propomos a falar sobre as lutas que nos propomos travar, primeiramente abordamos o contexto de violência e de ódio que tem se configurado.

Um espanto e estado perplexo de incompreensão nos abateu. $\mathrm{O}$ que esse abatimento tem a dizer à Psicologia que ansiamos criar? Por um lado, é preciso produzir esse campo problemático para indicar quais forças têm se embatido e como elas criam demandas à Psicologia. Por outro, nossas ações têm focado mais a definição das lutas do que tomado a própria condição que permite que a luta exista, enquanto um problema.
Este é um território bastante delicado, pois, é indiscutível que precisamos nos organizar e, para tanto, é imprescindível definir pautas, caminhos, estratégias. E temos feito tais movimentos, basta ver as redes que estabelecemos em termos de pesquisa em âmbito nacional e internacional, também as inserções em grupos, coletivos, militâncias, ocupações.

É um território delicado, ainda, pois talvez estejamos deixando escapar o fato de que ainda podemos criar as estratégias de enfrentamento, "porque há o direito ao grito. Então eu grito” (Lispector, 1981, p. 18). No entanto, neste momento, não temos a opção de não lutar, pois, não lutar seria não apenas abrir mão do direito ao grito, mas, fundamentalmente, aceitar que o grito e a luta não são necessários.

Estamos em perigo não porque temos que lutar por direitos, por representatividade, por modificação nas lógicas de violência e nos projetos de sociedade que exterminam, ruidosamente, à luz do dia e determinam decretos silenciosos na calada da noite. Estamos em perigo porque não podemos não lutar, não podemos não nos manifestarmos, não podemos não (re)agir. A aposta mais arriscada não é no âmbito do calar ou vociferar (como nos foi visibilizado nas ações na Praça da Alfândega), a aposta que não podemos perder e, primeiramente, não podemos não fazer é, juntamente, pelo fato de que não podemos não calar.

Agamben (2015), no texto Bartleby, ou da contingência, discute o conceito aristotélico de potência. Segundo o autor, a potência se atrela com a existência de contingências. Quando dizemos "eu posso" colocamos em jogo uma faculdade que não está, necessariamente, em ato, contudo, pode vir a ser exercitada em ato. Quando um escritor, por exemplo, não está escrevendo, ele é potente de escrever. Ao escrever, no entanto, passa-se da potência ao ato, sem o esgotamento, contudo, da potência mesma (Agamben, 2015).

$\mathrm{O}$ espaço entre o não escrever (potência) e o escrever (ato) faz com que o escritor se encontre em privação. Do mesmo modo que se pode escrever (potência), pode-se, ao contrário, não escrever (impotência). A impotência não seria, portanto, uma incapacidade, mas a possibilidade de manter-se em relação com aquilo que podemos. Outra discussão feita por Agamben (2010), desta vez mais detidamente sobre a forma de operação do poder e o modo como este incide sobre nossas vidas, é feita no texto Sobre o que podemos não fazer. 
Agamben (2010) revisita Deleuze que havia definido a operação do poder enquanto aquela intervenção que separaria os homens do que podem. Interceptar-se-ia a ação, na forma de uma proibição. Em uma análise distinta, Agamben afirmará que o poder não agiria “imediatamente sobre o que os homens podem fazer - sobre a sua potência -, mas antes sobre a sua impotência, isto é, sobre o que não podem fazer ou, melhor, podem não fazer" (p. 57). Isso implica em dizer que a expropriação e separação de um exercício ético incide, justamente, naquilo que, mesmo podendo fazer, nos seria possível não fazer. E é exatamente fundamental sustentar essa posição porque nossa força como potência, como luta, como condição de enfrentamento e resistência consiste na afirmação de uma escolha.

Compreendemos, então, que o acirramento dos processos de violência nos coloca dois problemas: primeiramente, nós ainda podemos produzir formas de resistência/lutar; e, ao contrário, se quisermos continuar com a possibilidade de resistir, não podemos não lutar. A questão da resistência se localiza justamente no ponto em que, quando somos separados daquilo que podemos fazer, ainda somos capazes de resistir: podemos não fazer. Contudo, quando o poder incide naquilo que podemos não fazer, isto é, sobre nossa impotência, somos separados do que nos possibilitaria resistir (Agamben, 2010).

Podemos afirmar que os processos de violência têm se expandido e abarcado cada vez mais âmbitos da vida política/social, não apenas pelas notícias que acompanhamos cotidianamente, mas pelo fato de que, neste momento, estamos separados da possibilidade de não lutar. O modo como o jogo político tem se organizado no Brasil aproxima-se muito mais da criação de condições nas quais, nós, não podemos não fazer. Não podemos não lutar. Não podemos não resistir. Não podemos não nos fazer presentes. Nãolutar, neste contexto, seria equivalente a nos rendermos definitivamente.

\section{Políticas de pesquisas e resistências}

A política de pesquisa na qual temos apostado é aquela que se atrela às lutas cotidianas fazendo crítica do próprio modo como nos colocamos em relação a elas. Que a Psicologia Social, assim como outras tantas psicologias e demais áreas do saber, tem empreendido tais batalhas é um fato constatável. Diferente, no entanto, são não apenas as proporções que nossos objetos de análise têm tomado, mas os meios pelos quais essas proporções são possibilitadas.

Estabelecer e fortalecer as redes com as quais enfrentamos as práticas de violência é somente uma das ações possíveis. Inserirmo-nos em coletivos, representações, autarquias são outras vias de entrada. Se essas estratégias configuram lutas localizadas, o conjunto de tais lutas produz o espaço de resistência. Se, como dissemos, a resistência se encontra sempre em relação a algo, nossa tarefa é fazer com que esse espaço em que uma relação é possível continue existindo. Muito embora, também como dito, os efeitos, em termos de resultados, tanto dos movimentos \#elenão e, também, as ações de virar voto, especialmente a que realizamos na Praça da Alfândega, não possam ser mensurados, não é menor ou desimportante o fato de que tais ações puderam ter existência nos espaços públicos.

Para que as lutas sejam realizáveis, é preciso preservar a possibilidade de que elas existam. É justamente essa possibilidade de existência das lutas que está em perigo no presente e, justamente, por isso estamos diante de uma impossibilidade de não lutar. Se para falar das lutas foi preciso dar nome aos processos de asseveramento da violência, não se tratou de reificar a violência, mas para alertar sobre os elementos que tem constituído o campo no qual tais violências e lutas têm sido travadas.

Não podemos não lutar se escolhemos por uma produção de conhecimento que não nos dissocia do que somos, do tempo em que vivemos, do mundo em que estamos. Não podemos não lutar porque uma ética da aposta na diversidade e na pluralidade da vida nos convoca. Não podemos não lutar porque queremos afirmar o espaço da liberdade em seu sentido mais vasto e amplo.

\section{Referências}

Agamben, G. (2004). Estado de exceção (2a ed.; I. D. Poleti, trad.). São Paulo, SP: Boitempo.

Agamben, G. (2005). Infância e história: Destruição da experiência e origem da história (H. Burigo, trad.). Belo Horizonte, MG: Ed. UFMG. 
Agamben, G. (2010). Sobre o que podemos não fazer. In G. Agamben, Nudez (pp. 57-60; M. S. Pereira, trad.. Lisboa: Relógio D’Água.

Agamben, G. (2014). Homo Sacer I: O poder soberano e a vida nua. (2a ed., H. Burigo, trad.). Belo Horizonte, MG: Humanitas.

Agamben, G. (2015). Bartleby, ou da contingência (V. Honesko, trad.). Belo Horizonte, MG: Autêntica.

Arendt, H. (2018). Sobre a violência. Rio de Janeiro: Civilização Brasileira.

Benjamin, W. (1986). Crítica da violência - Crítica do poder. In W. Benjamin, Documentos de cultura, documentos de barbárie: Escritos escolhidos (pp. 160-175; C. H. M. R. Sousa, trad.). São Paulo, SP: Cultrix. (Original publicado em 1921).

Benjamin, W. (2012a). O narrador. In W. Benjamin, Magia e técnica, arte e política: Ensaios sobre literatura e história da cultura (8a ed., pp. 213-240; S. P. Rouanet, trad.). São Paulo, SP: Brasiliense. (Original publicado em 1936).

Benjamin, W. (2012b). Sobre o conceito da história. In W. Benjamin, Magia e técnica, arte e política: Ensaios sobre literatura e história da cultura (8a ed., pp. 241-252; S. P. Rouanet, trad.). São Paulo, SP: Brasiliense. (Original publicado em 1940).

Bernardes, A. G., \& Marques, C. F. (2016). Psicologia da saúde: Articulações entre vida e política. Quaders de Psicologia, 18(3):69-81.

Boitempo. (2014). Agamben: O pensamento é a coragem do desespero. Recuperado de https://blogdaboitempo.com. $\mathrm{br} / 2014 / 08 / 28 /$ agamben-o-pensamento-e-a-coragem-do-desespero/

Carmo, C. M. (2016). Grupos minoritários, grupos vulneráveis e o problema da (in)tolerância: uma relação linguístico-discursiva e ideológica entre o desrespeito e a manifestação do ódio no contexto brasileiro. Revista do Instituto de Estudos Brasileiros, (64), 201-223. https://doi.org/10.11606/issn.2316-901X.v0i64p201-223

Carta Capital (2019, 26 de março). Bolsonaro determina comemorações do golpe de 1964. Recuperado de https://www.cartacapital.com.br/politica/bolsonaro-determina-comemoracao-do-golpe-de-1964/

Carvalho, A. G. P., \& Benvindo, J. Z. (2017). Os “imperativos da revolução de março" e a fundamentação da ditadura. Direito \& Práxis Revista, 9(1):113-145. https://doi.org/10.12957/dep.2018.26477

Decreto No 9.759, de 11 de abril de 2019. Extingue e estabelece diretrizes, regras e limitações para colegiados da administração pública federal. Brasília. Diário Oficial da União, 11 de abril de 2019.

Foucault, M. (2005a). O que são as Luzes. In M. B. MOTTA (Org.). Arqueologia das ciências e história dos sistemas de pensamento (pp. 335-351). Rio de Janeiro: Forense Universitária. (Coleção Ditos \& Escritos).

Foucault, M. (2005b). Em defesa da sociedade: Curso no Collège de France (1975-1976) (Coleção tópicos; M. E. Galvão, trad.). São Paulo, SP: Martins Fontes.

Foucault, M. (2008a). Segurança, território, população: Curso dado no Collège de France (1977-1978) (Coleção tópicos; E. Brandão, trad.). São Paulo, SP: Martins Fontes.

Foucault, M. (2008b). O nascimento da biopolítica: Curso dado no Collège de France (1978-1979) Coleção tópicos; E. Brandão, trad.). São Paulo, SP: Martins Fontes.

Foucault, M. (2013). A verdade e as formas jurídicas (E. Jardim, \& R. Machado, trad.). Rio de Janeiro, RJ: Nau.

Foucault, M. (2014). Do governo dos vivos (E. Brandão, trad.). São Paulo, SP:WMF Martins Fontes.

Foucault, M. (2015). A sociedade punitiva: Curso no Collège de France 1972-1973 (Coleção obras de Michel Foucault, I. C. Benedetti, trad.). São Paulo, SP:Wmf Martins Fontes.

Gagnebin, J. M. (2018). Walter Benjamin: Os cacos da história. São Paulo, SP: N-1 edições.

Galeano, G. B. (2017). Partiu rolezinho: Juventude, cidade, barbárie (Dissertação de mestrado). Faculdade de Psicologia, Universidade Católica Dom Bosco - UCDB, Campo Grande, MS, Brasil.

Kalil, I. O. (Coord.). (2018). Quem são e no que acreditam os eleitores de Jair Bolsonaro. São Paulo, SP: Fundação de Sociologia e Política de São Paulo.

Lei No 12.528, de 18 de novembro de 2011. Cria a Comissão Nacional da Verdade no âmbito da Casa Civil da Presidência da República. Diário Oficial da União, 28 de novembro de 2011. 
Lispector, C. (1981). A hora da estrela. Rio de Janeiro, RJ: José Olympio.

Miron, A. X., \& Guareschi, N. M. F. (2017). Compromisso social da Psicologia e sistema Único de Assistência Social: Possíveis articulações. Psicologia: Ciência e Profissão, 37(2):349-362. https://doi.org/10.1590/19823703000952014

Oliveira, L. (2011). Ditadura militar, tortura e história: A “vitória simbólica” dos vencidos. Revista Brasileira de Ciências Sociais, 26(75): 7-26. https://doi.org/10.1590/S0102-69092011000100001

Rocha, A. L. C., \& Eckert, C. (2000). A retórica do mito do progresso, “Brasil, um país sem memória!”. Iluminuras, 1(2): 2-16. https://doi.org/10.22456/1984-1191.9105

Rose, N. (2008). Psicologia como uma ciência social. Psicologia \& Sociedade, 20(2):155-164. https://doi.org/10.1590/ S0102-71822008000200002

Scarparo, H. B. K., \& Guareschi, N. M. F. (2007). Psicologia social comunitária e formação profissional. Psicologia \& Sociedade, 19(n esp 2): 100-108. https://doi.org/10.1590/S0102-71822007000500025

Scarparo, H. B. K., Torres, S., \& Ecker, D. D. (2014). Psicologia e ditadura civil-militar: Reflexões sobre práticas psicológicas frente às violências de estado. Revista EPOS, 5(1):57-78.

Scisleski, A. (2010). Governando vidas matáveis: as relações entre a saúde e a justiça dirigidas a jovens em conflito com a lei (Tese de doutorado). Faculdade de Psicologia, Pontifícia Universidade Católica do Rio Grande do Sul, Porto Alegre, RS, Brasil.

Silva, F. F. (2017). Psicologia no contexto da ditadura civil-militar e ressonâncias na contemporaneidade. Psicologia: Ciência e Profissão, 37(n esp.): 82-90. https://doi.org/10.1590/1982-3703060002017

\section{Giovana Barbieri Galeano}

Doutoranda em Psicologia Social e Institucional pela Universidade Federal do Rio Grande do Sul, Porto Alegre - RS. Brasil.

E-mail: giovanagaleano@hotmail.com

$$
\text { https://orcid.org/0000-0002-5293-6439 }
$$

\section{Neuza Maria de Fátima Guareschi}

Professora Adjunta do Programa de Pós-Graduação em Psicologia Social e Institucional do Instituto de Psicologia da Universidade Federal do Rio Grande do Sul, Porto Alegre - RS. Brasil.

E-mail: nmguares@gmail.com

(iD) https://orcid.org/0000-0001-5892-188X

\section{Andrea Cristina Coelho Scisleski}

Doutora em Psicologia pela Pontifícia Universidade Católica do Rio Grande do Sul, Porto Alegre - RS. Brasil.

E-mail: ascisleski@yahoo.com.br

(D) https://orcid.org/0000-0001-8387-0391

Endereço para envio de correspondência:

Universidade Federal do Rio Grande do Sul, Departamento de Psicologia. Av. Ramiro Barcelos, 2600, Santana.

CEP: 90035-003. Porto Alegre - RS. Brasil.

Recebido:20/06/2019

Aceito: 22/07/2019

Received:06/20/2019

Approved: 07/22/2019 
Psicologia: Ciência e Profissão 2019 v. 39 (n.spe 2.), e226327, 19-32.

Recibido:20/06/2019

Aceptado: 22/07/2019

Como citar: Galeano, G. B., Guareschi, N. M. F., \& Scisleski, A. C. C. (2019). Políticas de pesquisa e resistências em tempos de acirramento dos processos de violência. Psicologia: Ciência e Profissão, 39(n.spe 2), 19-32.

https://doi.org/10.1590/1982-3703003226327

How to cite: Galeano, G. B., Guareschi, N. M. F., \& Scisleski, A. C. C. (2019). Research policies and resistance policies in times of incitement of violence processes. Psicologia: Ciência e Profissão, 39(n.spe 2), 19-32.

https://doi.org/10.1590/1982-3703003226327

Cómo citar: Galeano, G. B., Guareschi, N. M. F., \& Scisleski, A. C. C. (2019). Políticas de investigación y resistencia en tiempos de intensificación de los procesos de violencia. Psicologia: Ciência e Profissão, 39(n.spe 2), 19-32. https://doi.org/10.1590/1982-3703003226327 